\title{
ВИВЧЕННЯ ТЕМПЕРАТУРНОЇ ЗАЛЕЖНОСТІ ДИНАМІЧНИХ ПАРАМЕТРІВ ВОДИ В ПОРОВОМУ ОБ'ЄМІ ВИКОПНОГО ВУГІЛЛЯ
}

\author{
А.Д. АЛЄКСЄЕВ, Т.А. ВАСИЛЕНКО, А.К. КІРІЛОВ, О.М. МОЛЧАНОВ, \\ Г.А. ТРОІЦЬКИЙ
}

Інститут фізики гірничих процесів НАН України

(C) 2012

(Вул. Р. Люксембург, 72, Донецък 83114; e-mail: tvasilenko@mail. ru)

\begin{abstract}
Подано результати дослідження температурних залежностей часів релаксації $T_{1}$ і $T_{2}$ та коефіцієнта самодифузї води $D$ у насичених вологою порах викопного вугілля (антрациту). Вимірювання проводили з застосуванням методів спін-ехо і ядерного магнітного резонансу (ЯМР) широких ліній. Резонансна частота для спінів ядер водню ${ }^{1} \mathrm{H}$ становила $f \approx 20$ МГц і температура $T$ змінювалася в інтервалі від $90 \mathrm{~K}$ до кімнатної. Результати досліджень свідчать про наявність "розмазаного" фазового переходу, що спостерігається в інтервалі температур $T=180-230 \mathrm{~K}$. Енергія цього фазового переходу, оцінена при використанні методу Уо-Федіна, становила $U_{0}=27-$ 35 кДж/моль. Показано, що енергія активації $E_{a}$, яка відповідає температурній залежності $T_{2}$, зростає при збільшенні $T$ від 4 кДж/моль $(90 \mathrm{~K})$ до 18 кДж/моль (300 K). Спостерігалося відхилення температурної залежності коефіцієнта самодифузії $D$ від ареніусової, що пояснюється переходом від об'ємної до поверхневої дифузї при зниженні температури.
\end{abstract}

\section{1. Вступ}

Різноманіття фізичних властивостей викопного вугілля і його хімічного складу, який зумовлений кількісною зміною супутних молекулярних сполук, характеризує стан вугільних пластів. Аналіз вугілля фізичними методами є надзвичайно важливим для прогнозу викидів газу й вугілля, які можливі у процесі видобутку вугілля. Серед таких методів є метод ядерного магнітного резонансу (ЯМР) [1]. Цей метод є ефективним засобом дослідження структури і сорбційних властивостей пористих сорбентів, наприклад, викопного вугілля $[1,2]$. Сучасні ЯМР спектрометри дозволяють вимірювати часи релаксації спінів протонів сорбатів, які містять водень, і отримувати важливу інформацію про розподіл пор за розмірами і рухливість молекул сорбату у поровому просторі [3]. Раніше з використанням імпульсного та безперервного ЯМР нами були досліджені процеси десорбції сорбатів (метану й води) з вугілля при кімнатній темпеpaтypi [4].
Основною метою даної роботи є дослідження температурних залежностей низки параметрів (спінспінового, $T_{2}$, спін-граткового $T_{1}$ часів релаксації та коефіцієнта самодифузії $D$ ), що характеризують рухливість молекул води у порах антрациту. Отримані з ареніусових залежностей цих величин енергії активації дають уявлення про механізм релаксації спінів ядер водню ${ }^{1} \mathrm{H}$ та рухливість молекул в умовах обмеженої геометрії пор.

\section{2. Матеріали і методика експериментальних досліджень}

У даній роботі проаналізовано вугілля марки А (антрацит пласт $h^{8}$ - "Наталья", шахта "2-2 біс", шахтоуправління "Шахтарськантрацит"; вихід летких речовин, $V^{\text {daf }}=4,8 \%$, вміст сірки, $S \approx 1 \%$; зольність, $A^{d} \approx 12 \%$ ).

Вугільні фракції з розміром частинок 2-2,5 мм насичували парами води в ексикаторі при кімнатній температурі. Далі для підготовлених таким чином зразків викопного вугілля визначали часи релаксації $T_{1}, T_{2}$ і коефіцієнт самодифузії $D$. Виміри проводилися на спектрометрі спін-ехо широких ліній з резонансною частотою $f \approx 20$ МГц ядерних спінів атома водню ${ }^{1} \mathrm{H}$.

У ролі модельних сорбентів досліджено також силікагелі з відомими розмірами пор. Деякі характеристики модельних пористих сорбентів, що використовувались у дослідженні, наведено у табл. 1.

Т а б ли ц я 1. Характеристики модельних пористих сорбентів, що використовуються у дослідженні

\begin{tabular}{cccc}
\hline Силікагель & Діаметр пор $d$, нм & Форма й розмір гранул \\
\hline SK-5a & 0,5 & циліндрична, \\
& & $h=7-10$ мм, $d=3$, мм \\
KCK-2 & 6,5 & сферична, $d=3$ мм \\
MПC-250 & 26 & сферична, $d=0,1 \mathrm{mм}$ \\
MCA-750 & 38 & сферична, $d=0,5$ мм \\
\hline
\end{tabular}


Для реєстрації спін-спінової релаксації використовували послідовність імпульсів Хана, для вимірювання $T_{1}$ застосовували двохімпульсну методику прогресивного насичення [5]. Для порівняння результатів імпульсного і автодинного методів для вугілля, насиченого водою, виміри проведено на стаціонарному ЯМР-спектрометрі. Час спін-спінової релаксації $T_{2}$ може бути оцінений по ширині лінії $\Delta B$ у гаусовому поданні, тобто $T_{2}=1,41 /(\gamma \Delta B)$, де $\gamma$ - гіромагнітне відношення для протона.

Вимірювання за низьких температур проводили при використанні проточного кріостата, що дозволяє підтримувати температуру в об'ємі контуру ЯМР спектрометра від $90 \mathrm{~K}$ до кімнатної температури. На першому етапі експерименту досягнуто мінімальної температури, і потім вона поступово збільшувалася та підтримувалася за допомогою терморегулятора 3 точністю $\pm 1 \mathrm{~K}$. Використання даної методики дозволяє надійно розділяти воду на об'ємну й зв'язану, що більш детально описано в $[1,6]$. Так проходив весь температурний діапазон фазового переходу води у пористій структурі антрациту у твердий (кристалоподібний) стан.

Апроксимацію залежності амплітуди сигналу спінехо від часу при визначенні $T_{1}$ і $T_{2}$ проводили в припущенні наявності двох протонних компонентів, що входять у сорбент і воду. У цьому випадку проводилося виключення сигналу спін-ехо, відповідального за релаксацію спінів ядер ${ }^{1} \mathrm{H}$ компоненти вугільної речовини, що містить водень. Крім того, сигнал спін-ехо, відповідальний за релаксацію спінів ядер ${ }^{1} \mathrm{H}$, при наявності двох станів води може бути розділено на дві окремі компоненти: більш зв'язана $(s)$ біля стінок пор і менш зв'язана (або вільна) $(f)$ в об'ємі великих пор.

Коефіцієнт самодифузії $D$ обчислено з апроксимації згасання амплітуди сигналу спін-ехо відповідно до виразу

$$
\begin{aligned}
& I(\tau)=a \exp \left(-2 \tau / T_{2 c}\right)+b \exp \left(-2 \tau / T_{2 x}\right) \times \\
& \times \exp \left\{-D\left(G_{0} \gamma\right)^{2}(2 \tau)^{3} / 3\right\},
\end{aligned}
$$

де $2 \tau$ - час затримки спін-ехо щодо першого імпульсу, $G_{0}=0,14$ Тл/м - градієнт індукції магнітного поля.

Температурні залежності часів релаксації $T_{1}$ i $T_{2}$ i коефіцієнта самодифузії $D$ досліджувалися як у напівлогарифмічних (ареніусових) координатах, так i у вигляді залежності $T_{1}$ і $T_{2}$ від температури у наближенні лінійного рівняння, що дозволяє визначити енергію активації $E_{a}$ і зробити висновок про механізм релаксації при збудженні спінів імпульсами радіочастотного діапазону.

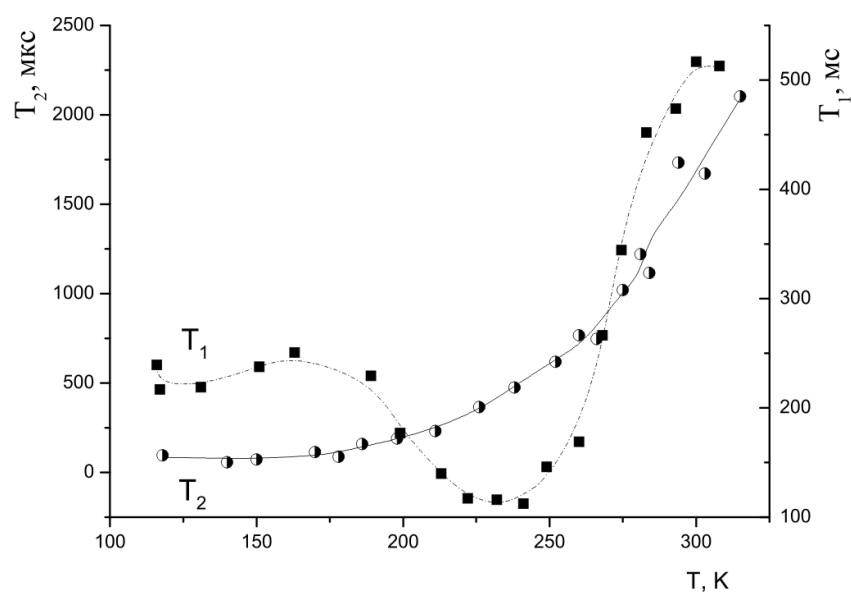

Рис. 1. Залежність від температури спін-граткового $T_{1}$ і спінспінового $T_{2}$ часів релаксації спінів ядер ${ }^{1} \mathrm{H}$ води у порах антрациту

\section{3. Результати та їх обговорення}

Характерні залежності сумарних часів спін-граткової $T_{1}$ і спін-спінової $T_{2}$ релаксації протонів води (вільної та зв'язаної) у порах антрациту показано на рис. 1.

Спочатку, при зниженні температури до $T \approx 225 \mathrm{~K}$ спостерігається зменшення спін-граткового часу релаксації $T_{1}$, а потім відбувається збільшення $T_{1}$ і вихід на певне стале значення. У точці мінімуму величини $T_{1}$ при $T \approx 225 \mathrm{~K}$ за наявності внутрішньомолекулярного диполь-дипольного механізму релаксації спінів виконується співвідношення $2 \pi f \tau \approx 1$ [5], що дозволяє оцінити час кореляції як $\tau \approx 8 \cdot 10^{-9} \mathrm{c}$.

За кімнатної температури час кореляції $\tau$ значно зменшується, і виконується умова $2 \pi f \tau \ll 1$. При цьому реалізується режим швидкої релаксації, для якого $1 / T_{1} \sim \tau$ [7]. Аналогічні температурні залежності $T_{1}$ 3 мінімумом у даному інтервалі температур спостерігалися і для інших пористих сорбентів [8]. Для антрациту така залежність отримана як для вільної $(f)$, так і зв'язаної $(s)$ компонент, що вказує на спільний механізм релаксації спінів ${ }^{1} \mathrm{H}$.

Енергія активації $E_{a}$, розрахована за температурною залежністю часу спін-спінової релаксації $T_{2}$, змінюється від $\approx 13$ кДж/моль при високих температурах до $\approx 4$ кДж/моль в області низьких температур $(T<170 \mathrm{~K})$ (рис. 2). Зменшення енергії активації $E_{a}$ при зниженні температури $T$ можна пояснити зменшенням об'ємної рухливості молекул сорбату і домінацією транспортування уздовж поверхні пор. Крім того, таке зменшення енергії активації при зниженні температури $T$ може відображати зміну механізму релаксації спінів сорбату, коли замість трансляційно- 


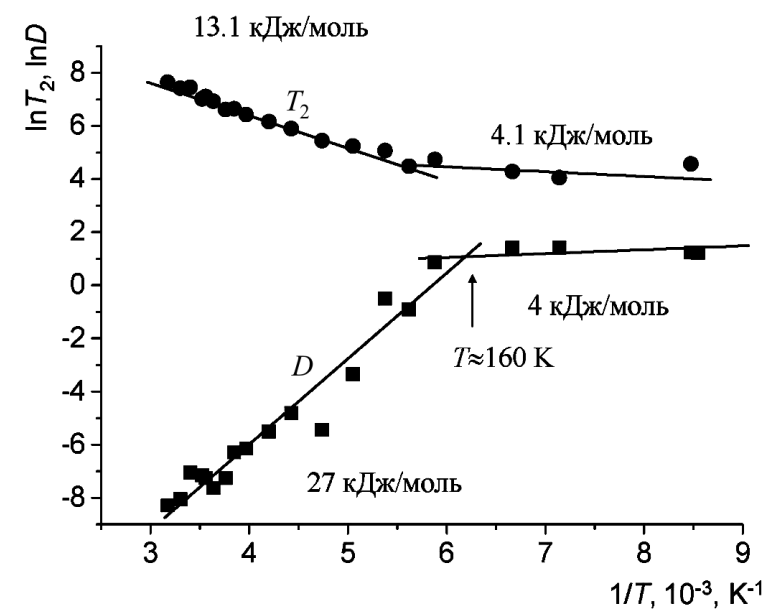

Рис. 2. Температурна залежність часу спін-спінової релаксації ${ }^{1} \mathrm{H}$ води $T_{2}$ і коефіцієнта самодифузії води $D$ в об'ємі пор антрациту

го диполь-дипольного механізму починає працювати спін-обертальний механізм релаксації спінів ${ }^{1} \mathrm{H}$ молекули води [9].

Коефіцієнт дифузіі води $D$ у порах антрациту збільшувався при зниженні температури $T$ (рис. 2), що є наслідком зміни механізму рухливості молекул води і наявності декількох фазових станів води в об'ємі пор. Усереднена енергія активації дифузії $E_{a}$, отримана для насичених вологою зразків антрациту 3 температурної залежності $D$, в ареніусових координатах при високих температурах $(T>170 \mathrm{~K})$ становила 27 кДж/моль. Відзначимо, що для цього ж вугілля з природним вмістом вологи отримано значення 52 кДж/моль, що відповідає наявності сильно зв'язаного компонента води. Спостережуване відхилення температурної залежності коефіцієнта самодифузії $D$ від ареніусової при $T \approx 170 \mathrm{~K}$ можна пояснити переходом від об'ємної до поверхневої дифузії при зниженні температури [10].

Відзначимо, що спостерігалася добра відповідність між даними, отриманими при використанні методу спін-ехо й стаціонарного ЯМР. Наприклад, при $T=$ $294 \mathrm{~K}$ час спін-спінової релаксації $T_{2}$ об'ємної води, оцінений з ширини лінії ЯМР $\Delta B \approx 0,185$ Гс, становив $T_{2}=1,41 /(\gamma \Delta B) \approx 1790$ мкс у порівнянні 3 значенням $T_{2} \approx 1732$ мкс, отриманим методом спінexo.

Результати двох застосованих ЯМР методик свідчать про наявність "розмазаного" фазового переходу води в порах вугілля (антрациту) у температурному інтервалі 180-230 K. Енергію цього фазового переходу оцінено при використанні формули Уо-Федіна [11]
$U_{0}=154,5 \cdot T$ кДж/моль, де $T \approx 180-230 \mathrm{~K}$ і вона становить 27-35 кДж/моль.

В інтервалі температур вищих за мінімум ( $\approx 220 \mathrm{~K}$, рис. 1) коефіцієнти трансляційної дифузії $D$ можна оцінити також за виміряними величинами $T_{1}$. При внутрішньо-молекулярному диполь-дипольному механізмі релаксації зв'язок між коефіцієнтом трансляційної дифузії $D$ і $T_{1}$ визначається виразом $D=$ $0,25 \cdot 10^{-8} T_{1} \mathrm{~m} / \mathrm{c}^{2}[4]$, де $T_{1}$ виражено в с.

При цьому в релаксації ЯМР розділяються два внески, що відповідають сорбованій і вільній (об'ємній) воді у порах. У табл. 2 наведено виміряні значення $T_{1}$, обчислено коефіцієнти дифузії $D$ для сорбованої $(s)$ і вільної $(f)$ води у порах антрациту при різних температурах $(T=211-283 \mathrm{~K})$.

Для вільної води значення $D$ приблизно на 1 порядок вищі, ніж для сорбованої. Оцінені з цих даних енергії активації $E_{a}$ становили $4,1 \pm 1,9$ кДж/моль і $13,1 \pm 2,2$ кДж/моль для сорбованої $(s)$ і вільної $(f)$ води відповідно. Більш висока енергія активації для вільної води вказує на більшу рухливість молекул, віддалених від поверхні пор, а менша енергія активації відповідає тому, що сорбовані молекули води мають тільки обертальний ступінь свободи поблизу активного центра.

Для антрациту, який має найменші за діаметром пори серед вугілля у ряді метаморфізму, $U_{0} \in$ найменшою [2]. Спостерігається така ж тенденція зменшення енергії активації поблизу температури фазового переходу, що пояснюється зменшенням кількості ступенів свободи руху молекул води при низьких температурах в умовах обмеженої геометрії пор.

Відзначимо, що результати дослідження за допомогою ЯМР-методів у вугіллі марки А при низьких температурах підтверджують закономірності поводження динамічних характеристик молекул води, отриманих для інших пористих середовищ $[12,13]$.

Т а б л и ц я 2. Експериментальні значення часу поздовжньої релаксації $T_{1}$ i коефіцієнта дифузії $D$ як функція температури $T$ для сорбованої $(s)$ і вільної $(f)$ фракцій води в порах антрациту

\begin{tabular}{c|c|c|c|c}
\hline$T, \mathrm{~K}$ & $T_{1 s}, \mathrm{Mc}$ & $D_{s}, 10^{-10} \mathrm{~m}^{2} / \mathrm{c}$ & $T_{1 f}, \mathrm{Mc}$ & $D_{f}, 10^{-9} \mathrm{~m}^{2} / \mathrm{c}$ \\
\hline 283 & 77,2 & 1,93 & 892 & 2,23 \\
274 & 61,7 & 1,54 & 692 & 1,73 \\
266 & 66,3 & 1,66 & 871 & 2,18 \\
260 & 60,7 & 1,50 & 412 & 1,04 \\
252 & 60,9 & 1,50 & 572 & 1,43 \\
238 & - & - & 199 & 0,50 \\
227 & - & - & 269 & 0,67 \\
\hline
\end{tabular}




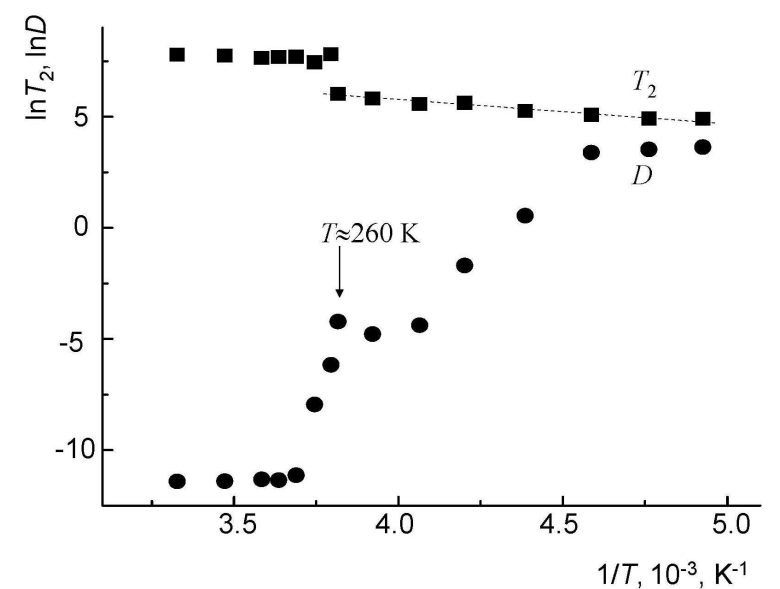

Рис. 3. Температурні залежності часу спін-спінової релаксацї води $T_{2}$ і коефіцієнта самодифузії $D$ води в порах силікагелю МПС-250

Для пояснення закономірностей, отриманих для води у порах антрациту, за методикою, що наведена вище для антрациту, були досліджені насичені водою зразки силікагелів, що мають різний діаметр пор. Загалом для силікагелів, які мають вузькі піки в розподілі пор за розмірами, спостерігалося, що температура фазового переходу досить чітко фіксується на температурній залежності $T_{2}$ в ареніусових координатах. Така поведінка відрізнялася від поведінки, що спостерігалася для води у порах антрациту, де розширення лінії поглинання (або зменшення часу релаксації $T_{2}$ ) відбувається в досить протяжному інтервалі температур.

На рис. 3 наведено приклад температурних залежностей часу спін-спінової релаксації води $T_{2}$ i коефіцієнта самодифузіі $D$ води у порах силікагелю МПС-250, середній розмір пор якого становить 26 нм (див. табл. 1). На цих залежностях при температурі $T \approx 260 \mathrm{~K}$ добре фіксується фазовий перехід (показано стрілкою), що відповідає різкій зміні рухливості води. Енергія фазового переходу молекул води в цьому пористому сорбенті відповідно до Уо-Федіна [11] дорівнює $U_{0}=40,6$ кДж/моль. Аналогічна поведінка спостерігалась для води у порах силікагелю МСА-750 з більшим розміром пор. Воду в силікагелях з великим розміром пор МПС-250 (26 нм) і МСА-750 (38 нм) можна чітко розділити на два компоненти: вільну воду і сорбовану на активних центрах поверхні пор. Деякі властивості води у порах можна пояснити наявністю обміну між двома компонентами, що мають різні рухливості [14].

Цікаві зміни в динаміці протонів ${ }^{1} \mathrm{H}$ води спостерігалися у порах силікагелю KCK-2 з меншим розміром

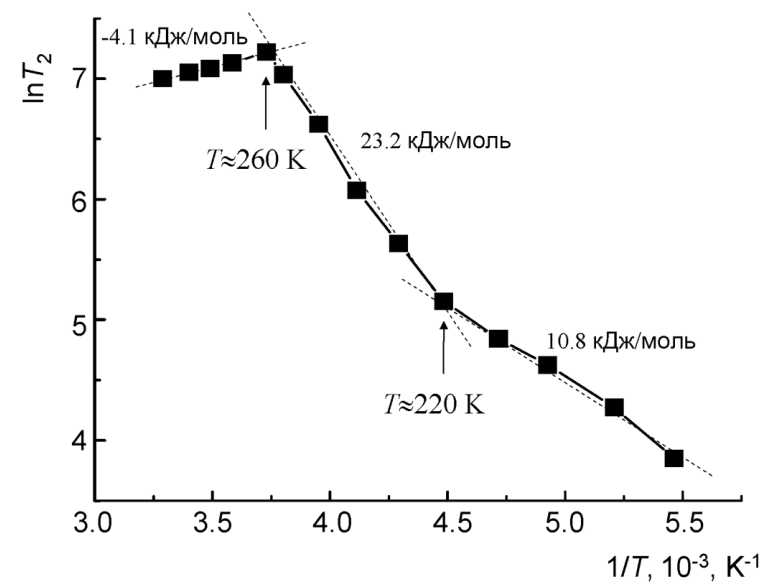

Рис. 4. Температурні залежності часу спін-спінової релаксації води $T_{2}$ в порах силікагелю $\mathrm{KCK}-2$

пор 6,5 нм (рис. 4). На температурній залежності часу спін-спінової релаксації води $T_{2}$ в ареніусових координатах тут можна виділити три лінійні ділянки 3 різними енергіями активації: $E_{a}=-4,1$ кДж/моль для високотемпературної області $(T>260 \mathrm{~K}), E_{a}=$ 23,2 кДж/моль в інтервалі $222 \mathrm{~K}<T<270 \mathrm{~K}$ i $E_{a}=10,8$ кДж/моль в низькотемпературному інтервалі $182 \mathrm{~K}<T<222 \mathrm{~K}$.

Аналогічно на температурній залежності часу спінспінової релаксації $T_{2}$ для силікагелю SK-5а з найменшим розміром пор 0,5 нм в ареніусових координатах можна виділити дві лінійні ділянки з різними енергіями активації: $E_{a}=15,3$ кДж/моль для високотемпературної області $(T>230 \mathrm{~K})$ (це значення $E_{a}$ є близьким до $E_{a}$ об'ємної дифузї води) і $E_{a}=4,0$ кДж/моль при низьких температурах. Таким чином, при нижчих температурах трансляційна рухливість води знижується і величина $E_{a}=4,0$ кДж/моль відповідає обертальним ступеням вільності молекул води, сорбованих на поверхні пор. У силікагелі SK-5а 3 найменшим розміром пор спостережувані ефекти характеризують рухливість води за наявності істотних геометричних обмежень. В об'ємі таких мікропор стримується утворення кластерів води, і властивості молекул води відповідають сорбованим у моношарі молекулам на поверхні.

У цілому дослідження модельних пористих сорбентів з різним розміром пор (табл. 1) показало, що температура, при якій відбувається зміна рухливості і зменшується кількість ступенів вільності молекул води під час руху зменшується при зменшенні діаметра пор. На рис. 5 наведено залежність енергії активації $E_{a}$ для $T_{2}$ від діаметра пор $d$ в низькотемпературній області температур фазового переходу. Відзначимо, 


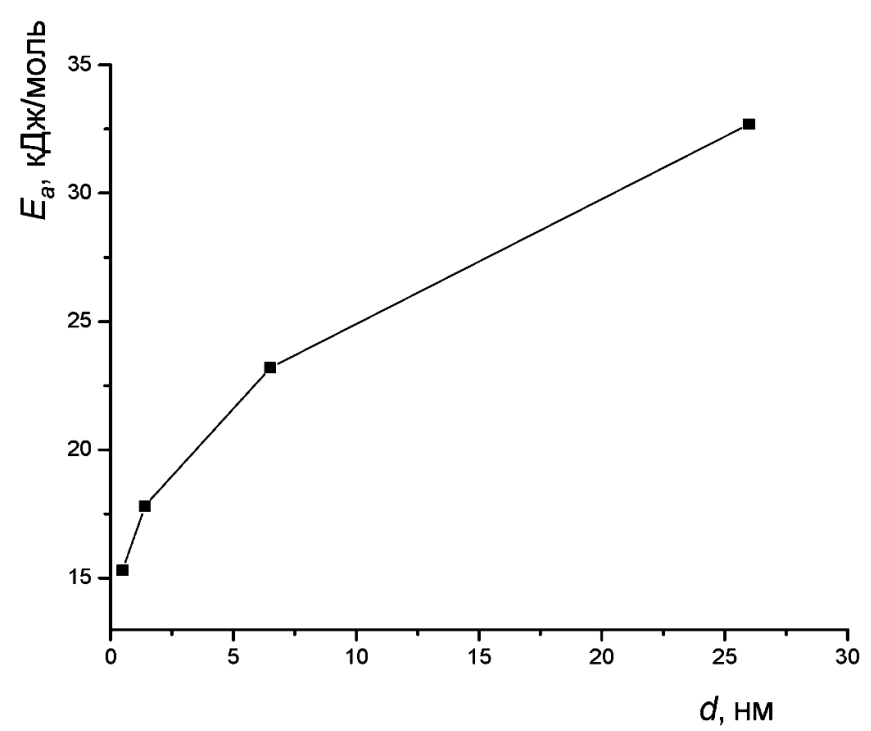

Рис. 5. Залежність енергї активації $E_{a}$ від діаметра пор $d$. Отримана $з$ ареніусових залежностей для часу релаксації $T_{2}$ води у порах силікагелів (табл. 1)

що величина $E_{a}$ зростає при збільшенні $d$ і це добре корелює з аналогічною залежністю для енергії фазового переходу $U_{0}$ води у порах вугільних зразків різної стадії метаморфізму $[2,15]$.

\section{4. Висновки}

Результати дослідження методами ЯМРспектроскопії води у порах антрациту в інтервалі температур від $90 \mathrm{~K}$ до кімнатної показали існування різкої зміни рухливості їі молекул. Спостерігалася аномальна неареніусова температурна поведінка коефіцієнтів самодифузіі. Таку поведінку можна пояснити специфікою температурної залежності внесків об'ємного й поверхневого транспортування в дифузію води, що знаходиться в мікропорах антрациту. Показано, що при низьких температурах молекули води, пов'язані з активними центрами на поверхні пор, мають один обертальний ступінь вільності 3 енергією активації, що близька до $E_{a}=4$ кДж/моль. Продемонстровано існування "розмазаного" фазового переходу для води в порах вугілля, що спостерігається в інтервалі температур $T=180-230$ K. Енергія цього фазового переходу, оцінена за допомогою методу Уо-Федіна, становила $U_{0}=27-35$ кДж/моль. Дослідження модельних пористих сорбентів, що мають вузькі піки у розподілі пор за розмірами, показали, що фазовий перехід для води у цих порах чітко фіксується при певній температурі, яка зменшується при зменшенні діаметра пор $d$. Для модельних сорбентів енергія активації $E_{a}$, отримана 3 ареніусових залежностей для часу релаксації $T_{2}$, зростає при збільшенні $d$, і це добре корелює з раніше отриманою залежністю для енергії фазового переходу $U_{0}$ води у порах вугільних зразків різної стадії метаморфізму.

1. А.Д. Алексеев, В.Е. Зайденварг, В.В. Синолицкий, Е.В. Ульянова, Радиофизика в угольной промышленности (Недра, Москва, 1992).

2. А.Д. Алексеев, Т.А. Василенко, Е.В. Ульянова, УФН 175, 1217 (2005).

3. G.Q. Zhang and G.J. Hirasaki, J. Magnetic resonance 163, 81 (2003).

4. Т.А. Василенко, А.К. Кириллов, Г.А. Троицкий, А.Н. Молчанов, Г.П. Стариков, ФТВД 18, 128 (2008).

5. А.А. Вашман, И.С Пронин, Ядерная магнитная релаксачионная спектроскопия (Машиностроение, Москва, 1986).

6. А.Д. Алексеев, Г.П. Стариков, Т.А. Василенко и др., Вісті Донецького гірничого інституту. Донецьк, ДНТУ 1, 174 (2005).

7. E. Lang, H.D. Lüdemann, J. Chem. Phys. 67, 718 (1977).

8. J. Beau, W. Webber, Nuclear Magnetic Reson. Spectr. 56, 78 (2010).

9. F. Mallamacea, M. Broccio, C. Corsaro et al., J. Chem. Phys. 124, 161102 (2006).

10. В.И. Ролдугин, В.М. Жданов, В.В. Волков, Структура и динамика молекулярных систем, Эл. журн. №4, $84(2008)$.

11. Дж. Уо, Э.И. Федин, Физика твердого тела 4, 2233 (1962).

12. Faraone, L. Liu, C.J. Moi et. al., J. Chem. Phys. 121, 10843 (2004).

13. В.И. Бетехтин, А.Н. Бахтибаев, Е.А. Егоров и др., Цемент № 10, 8 (1989).

14. Дж. Белфорт, Н. Синаи, Вода в полимерах, С. Роулен (ред.), (Мир, Москва, 1984).

15. А.Д. Алексеев, Т.А. Василенко, А.К. Кириллов, А.Н. Молчанов, Г.А. Троицкий, А.В. Дончук, ФТВД 20, 133 (2010).

Одержано 17.03.2011 


\section{ИЗУЧЕНИЕ ТЕМПЕРАТУРНОЙ ЗАВИСИМОСТИ \\ ДИНАМИЧНЫХ ПАРАМЕТРОВ ВОДЫ В ПОРОВОМ ОБЪЕМЕ ИСКОПАЕМОГО УГЛЯ}

\author{
А.Д. Алексеев, Т.А. Василенко, А.К. Кириллов, \\ А.Н. Молчанов, Г.А. Троицкий \\ $\mathrm{P}$ е $з$ ю м е
}

Даны результаты исследований температурных зависимостей времен релаксации $T_{1}, T_{2}$ и коэффициента самодиффузии воды $D$ в насыщенных влагой порах ископаемого угля (антрацита). Измерения проводили с использованием метода спинэхо и ядерного магнитного резонанса (ЯМР) широких линий. Резонансная частота для спинов ядер водорода ${ }^{1} \mathrm{H}$ составляет $f \approx 20$ МГц и температура $T$ изменялась в интервале от $90 \mathrm{~K}$ до комнатной. Результаты исследований свидетельствуют про присутствие "размазанного" фазового перехода, что наблюдается в интервале температур $T=180-230 \mathrm{~K}$. Энергия этого фазового перехода, оцененная при использовании метода Уо-Федина, составляет $U_{0}=27-35$ кДж/моль. Показано, что энергия активации $E_{a}$, которая отвечает температурной зависимости $T_{2}$, увеличивается при увеличении $T$ от 4 кДж/моль $(90 \mathrm{~K})$ до 18 кДж/моль $(300 \mathrm{~K})$. Наблюдалось отклонение температурной зависимости коэффициента самодиффузии $D$ от арениусовой, что объясняется переходом от объемной до поверхностной диффузии при снижении температуры.

\section{TEMPERATURE DEPENDENCES OF DYNAMIC PARAMETERS OF WATER IN FOSSIL-COAL PORES}

\author{
A.D. Alexeev, T.A. Vasilenko, A.K. Kirillov, \\ O.M. Molchanov, G.A. Troitsky
}

Institute for Physics of Mining Processes,

Nat. Acad. of Sci. of Ukraine

(72, R. Luxemburg Str., Donetsk 83114, Ukraine;

e-mail: tvasilenko@mail.ru)

$\mathrm{S} u \mathrm{~mm}$ a r y

The results of nuclear magnetic resonance (NMR) studies of water relaxation times, $T_{1}$ and $T_{2}$, and self-diffusion coefficients, $D$, in water-saturated pores of fossil coal (anthracite A) are reported. The spin-echo and broad-line NMR measurement techniques were used. The resonance frequency of ${ }^{1} \mathrm{H}$ spins was found to equal $f \approx 20 \mathrm{MHz}$ in the temperature, $T$, range from $90 \mathrm{~K}$ to room temperature. The results of experiments evidence the existence of a smeared phase transition in the temperature range $T=180 \div$ $230 \mathrm{~K}$. Using the Uo-Fedin technique, the corresponding phase transition energy was estimated to be $U_{0}=27 \div 35 \mathrm{~kJ} / \mathrm{mol}$. The activation energy $E_{a}$ associated with the $T_{2}(T)$ dependence was found to increase from $4 \mathrm{~kJ} / \mathrm{mol}$ at $T=90 \mathrm{~K}$ to $18 \mathrm{~kJ} / \mathrm{mol}$ at $T=300 \mathrm{~K}$. The deviation of the temperature dependence of the self-diffusion coefficient $D$ from the Arrhenius law was explained by the change-over from the bulk diffusion mode to the surface one as the temperature decreased. 